\title{
Auto-Stirring Grains Bed Dryer as an Innovative Efficiency Solution
}

\author{
Dandy Z. Sjechlad ${ }^{1,2}, J$ Jamari $^{3}$, and $S A$ Widyanto $^{3}$ \\ ${ }^{1}$ Doctoral Program of Mechanical Engineering, Diponegoro University, Semarang - Indonesia \\ ${ }^{2}$ Engineering Business Unit Division, PT Pura Barutama, Kudus - Indonesia \\ ${ }^{3}$ Department of Mechanical Engineering, Faculty of Engineering, Diponegoro University, Semarang - Indonesia
}

\begin{abstract}
The government has budgeted assistance/grants continuously many bed dryers to farmers but many of them were not used because farmers felt that the drying production rate of rice is more expensive than the traditional open sun drying. The farmers choose to go back to the traditional way that takes the drying process longer than using the dryer. For 1 year, open sun drying can process 100 batches, and dryer can process 450 batches. This research tries to solve the high cost problem by looking for a new alternative solution. The solution is replacing the oil burner with a rice husk burner, which is appropriate both economically and environmentally. For the stirring mechanism, this system must continuously stir up the pile of grains during the drying process. The point must be fulfilled is that the total cost of the drying process should not rise, especially the cost of the stirring process. A stirrer mechanism that needs smaller power than the maximum power setting is made. Farmers' income for this innovative modification will get a $332 \%$ increasing profit than using oil burner bed dryer machine and will get a $41 \%$ increasing in welfare than using the standard husk burner bed dryer.
\end{abstract}

Keywords: Paddy; Dry; Stirring; Husk; Grains; Mechanism.

\section{Introduction}

To support the agricultural economic cycle, stimulate/promote agricultural growth [1], and support independence food security and agricultural [2], the Government through the Ministry of Agriculture has budgeted assistance/grants continuously in Indonesia. Through the Agricultural Research and Development Centre of the Indonesian Ministry of Agriculture in Bogor, it has also been discussed plans involving elements of machinery innovation can drive progress and competitive advantage in the world of agriculture in developing economies [3].

To minimize the post-harvesting losses and increase the quality of grains in the rice production cycle, it is important for farmers to involve mechanization in the rice drying process. After harvesting time, we should directly dry the grains less within 24 hours to minimize those losses and evaporate the moisture content inside the rice and reduces it from $24 \%-26 \%$ on a wet basis after harvested to at least $14 \%$ and a good $12 \%$. A drying process that is not complete or even late/delay will cause a loss in quality and/or quantity of grains. One of the implementations is the grant of a variety of rice/crops drying machines [4-6]. The Indonesian National Budget (APBN) has been allocated for many years and also some of it had been delivered hundreds of Flat Bed Dryer grants from the Ministry of Agriculture and the Ministry of Village, Development of Disadvantaged
Regions and Transmigration to Gapoktan (Combined Farmer Groups). This flatbed dryer means that the simple principle an open flat chamber with two segments separated by a horizontal screen where the lower space is a pressure stabilizer chamber which has an intake of hot air flow from the burner, and the outlet leads to open space on the upper side through the horizontal screen. An upper open chamber is a place for wet grains/crops to be dried. The dry air that is flowing from the lower bulkhead chamber will penetrate the wet grains layer resulting in the grains drying process [7]. The heat from the oil burning process is taken by airflow through the Open Combustion process at Oil Burner which can be either direct or indirect combustion.

However, many of these assistance were not utilized by farmers at all which then led to the omission by the Gapoktan. Already billions of government assistance were abandoned by farmers because they feel that these tools cannot help the welfare so they choose to go back to the process of drying grains, corn, or beans that use the open sun by drying it out, the drying process is very long and unstable. In dry season conditions, it takes approximately 1.5 days (12 hours) to reach $14 \%$ dryness. The process of Open Sun Drying can be seen in Fig. 1. The drying rate of the open sun drying type is highly dependent on the radiant heat of the sun and also the wind. The residual part of solar energy is absorbed by the crop surface depends upon the colour of crops. Heat gained by crop results in wavelength radiation loss,

* Corresponding author: dsjechlad@gmail.com 
convection loss and mass transfer from the surface of the crop to ambient air through moist air. The role of blowing air speed is very decisive in the progress of evaporation and convective heat loss. The grains are dried because of evaporative losses due to reduced moisture [8]. In open sun drying, everything is natural and uncontrollable. The drying parameter like moisture content, temperature, heat input, and drying air flow rate, etc. can change every time everywhere and not necessarily the same, repeated from the previous day [9].

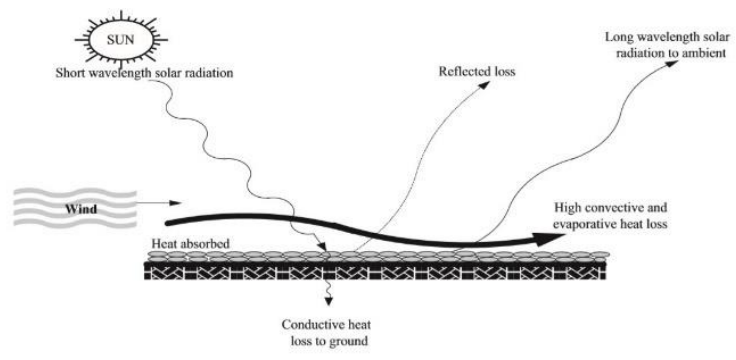

Fig. 1. Process of Open Sun Drying [10]

If traced and analyzed, the cause of omission is farmers think that the cost of diesel fuel as drying fuel is very expensive. This analysis can be seen in Table 2 . This is very sensitive to the increase in diesel fuel prices. The other reason is the need for a labour-intensive stirring process so that farmers have to spend in advance some amount of stirring power. A minimum of 4 mixers wearing boots and masks during the drying process, which implies 8 hours continuously, the operators will come in contact with sharp grains silica. The thing makes it sometimes become worse is the availability of the stirring workforce if the operating frequency is normal, which is around three batches $/ 2$ days. The last but not least, Gapoktan management that is not professional so the maintenance and operation are finally constrained by funds. Government assistance is only investment-oriented. Maintenance and repair costs will be needed later which should be done collectively by Gapoktan through contributions from members.

The Central Government has donated many units of the flatbed dryer to Gapoktans. The reason why the dryer is needed by farmers is that even though the traditional open sun drying method only relies on people to spread and stir, the processing time is very long. The process can only be carried out during 12 sun hours of heat, while with dryer the drying process is carried out for 8 hours which can be done at any time, both day/night, dry or rainy season. Not to mention the losses caused by colour loss because of the UV exposure; insects, birds, micro-organisms; dust and dirt contamination; the threat of strong winds blow, thunderstorm, rain; insufficient or even excessive drying; and also large area required; etc. [10]. The drying zone can be seen in Fig. 2. Although the drying cost of open sun drying is only a variable cost of around Rp.150, - per kilograms for drying for 12 hours (1.5 days), but the long drying conditions cause farmers to only be able to dry twice the process every three days. When compared to Dryer, drying takes place in 8 hours of processing, or 3 times the process in 2 days, it can be imagined if 1 year process, assuming the rainy season and other disturbances cause the number of effective days open sun drying is only 150 days, then the number of batches are only 100 times the process, compared to Dryer which can be 450 times the process.

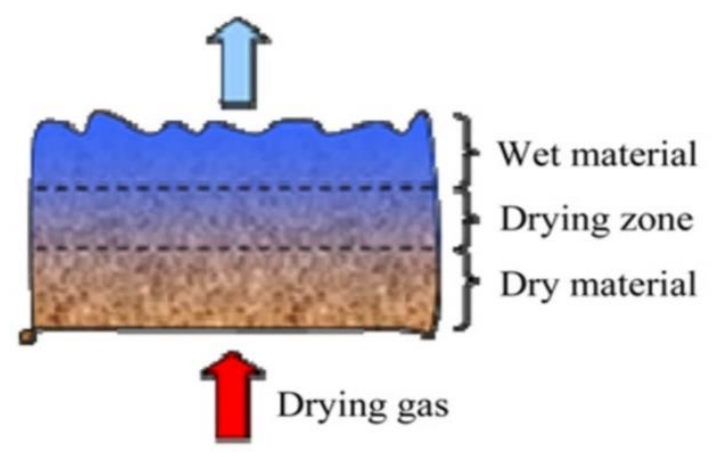

Fig. 2. Drying Zone [7]

However, the reality felt by Drying Production Rate farmers per kilogram of rice is more expensive than Drying Production Rate for open sun drying, so they choose to dry traditionally with the consequence of less dry grains produced, and they only share the results with workers in the form of Rp.150, - per $\mathrm{kg}$ without any other fees, including any number of workers. The price is the same.

Government spending is a unique type of market. Unlike the private market where buyers are the ones who feel the value of benefits, in the government spending market, the government is the buyer, while the audience is Gapoktans and farmers. The condition of the utilization of the machine felt by Gapoktans and farmers were not accommodated and flowed to the government. Another factor is that Gapoktans thinks that it is not costly to get the aid machine, so they do not feel very disadvantaged if the device is abandoned because it does not match the performance expectations.

The improvement will be approached in an alternative heat generator and innovative stirring mechanism. The first area, alternative new burning material that is cheaper but still able to deliver the number of calories which is relatively the same as the time needed. The second area is an alternative process that can help reduce the number of workers needed, or even eliminate the dependence of labourers to stir up grains. The resulting solution must be sturdy, not easy to wear and minimal parts so that the maintenance costs needed are not large.

\section{Methodology}

In answering the problem of this case, the author will use the Engineering Design/Product Design [11]. It will be discussed, analysed and solved with stages starting from Product Ideas, Definitions, Limits; Design Criteria; Product Concept; and Provision of Product Forms.

A new generation of flatbed dryer will be designed that can fulfill the basic desires of farmers, a new 
initiative flatbed dryer that can provide more advantages and more efficient compared to traditional proper methods like; open sun drying and standard flatbed dryer being discussed earlier (with burning oil) or even with rice husk burner flatbed dryer. This innovative solution must utilize biomass or rice husk as a heat source as an alternative substitute for existing burning oil, and must be able to dry the grains with the same quality like a standard flatbed dryer but it is more efficient in the operating cost, and in total, must provide more lower in drying cost rate (combined with capital expenditure and operational expenditure). The new solution must give the revitalization of an ordinary flatbed dryer system with the automation system.

For the boundary/design criteria, it must be set for the criteria; the new system shouldn't use diesel fuel or fossil fuel as a source of drying calories. It must use rice husk or biomass as a calorie-producing ingredient; Total drying production cost rate must be lower than the traditional bed dryer, and even the ordinary drying process by drying and utilizing sunlight (open sun drying); Do not require human assistance during the drying process other than one operator who oversees and runs the machine; Firm and has a long useful life investment; Safe in operation; The new system is an attachment to ordinary flatbed dryer so it should utilize the same body/chamber of ordinary one; It must be ensured that the operator or human skin contact involved is a little possible with grains. Grains skin contains very high silica [12] which will cause itching due to the scratching of the skin of grains with human skin, and also the sharp silica properties.

For the expected criteria, the dryer must cheap, the price is not much higher compare to ordinary flatbed dryer, Easy assembly process and knockdown install system, at least almost the same easy as ordinary flatbed dryer, Easy shipping process, at least not much harder or requires more carrier size than ordinary Bed Dryer, No more difficult than traditional bed dryer in maintenance and treatments. The function block of the process and block diagram of the process can be seen in Fig. 3 and Fig. 4 respectively.

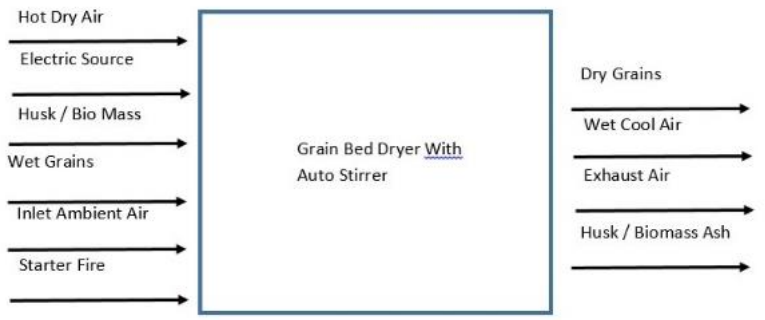

Fig. 3. Function Block of the Process

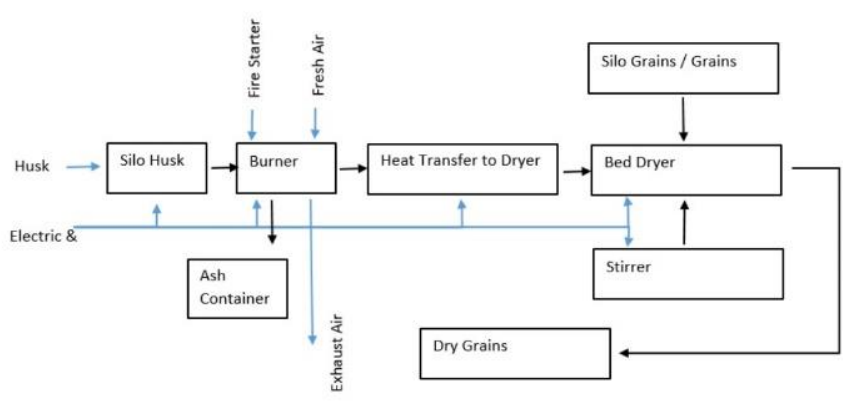

Fig. 4. Block Diagram of the Process

For Product Concept, the resulting product must be able to produce a lower production drying rate and must provide the much better profit per month compared to the traditional bed dryer and also open sun drying that is stated in Table 2.

\section{Result and Discussion}

According to the analysis [13], it was mentioned that Asia was the center of rice production. $90 \%$ of the world's rice comes from Asia. So that husk, which is the waste of the milling process from rice, has the potential to be used as a special energy source for the conversion of chemistry to calories.

It was also added that the use of rice husk will keep the pace of Global Warming because the carbon released in the chemical reaction process is the same element that was absorbed when paddy grows [14]. So that the residue from agriculture has zero net $\mathrm{CO}_{2}$ emissions to the environment. Unlike fossil, the carbon inside has been saved thousands of years so that the release when reacting will cause imbalances in the environment and cause a greenhouse effect.

On the side of rice husk's waste, direct combustion will produce Ash and Fly Ash with a $\mathrm{SiO}_{2}$ dominant element of $87 \%-91 \%$. This $\mathrm{SiO}_{2}$ is an excellent material for building materials, glass, ceramic, and cement. This was discussed more deeply by Fernandes [15] that the chemical and physical content of Rice Husk Ash (even its grains) is largely determined by the type of soil where they growth, harvest period, harvest way, fertilizer content, and up to its combustion process which will produce physical and chemical properties different. This is important for optimizing the use of waste. Polymers and Synthetic are in great need of fine grains from the results of Fluidized Direct Combustion while the type of Coarse-grained Suspension Dryer is well used for building materials and construction due to its larger surface area. Rice husk ash also a renewable source for Zeolite $\mathrm{Y}$ in sodium form (NaY) [15].

The second area that will be touch is a revitalization of flatbed dryer with automation. In the agricultural industry in Indonesia, there are two known patterns of the basic process of grains drying using dryer, namely Vertical Dryer, where the grains are circulated during the drying process; and a bed dryer where the pile of grains stays unmoving in a container or chamber, and the flow 
of hot air breaks through the grains from below to above. This is the speciality of Vertical Dryer. It can do intermittent or tempering drying approaches in which the heat is applied intermittently. The $1 / 4$ portion of cycles the grain will be dried mix flow or cross-flow crossing with hot dry air. Then the $3 / 4$ portion of cycles in the tempering period, the grains will do resting then the moisture of grains will be redistributed inside the material. Drying on the core of the grain will be longer than the outer portion of grain. So that when drying is pursued to the core, the outer layer will be excessively dry. On the other hand, if drying chases the drought in the outer layer then the moisture content at the core still high. With the tempering period, this process will avoid cracking material and increase the efficiency of drying cost [16]. The tempering approach, which is treating the drying process with two phases, which finally resulted in a wind-up process greatly affected the rice quality results because it reduced stress from the grain's core [17]. If drying with hot air is carried out continuously, then at the core of the grains stress will arise which will cause broken grains in the milling process. This tempering distinguishes the Vertical Dryer compare to the bed dryer system where the grains when spinning one cycle will be crossed with dry air for $25 \%$ of the rotation time, and the remaining $75 \%$ is carried out in the tempering phase. Whereas in the bed dryer, the grains stay in the chamber. It takes a stirring effort, and even then to homogenize the drought in the grains, not the tempering process. In bed dryer, due to evaporation of the bottom layer, the steam evaporates and then migrates to the layer above it, resulting in few hours after starting the drying process, moisture content at the top layer of the grains will be increased [18]. However, because the investment price is very different almost twice and the topic of development is a revitalization of bed dryer for government assistance, the focus of the discussion is only on the flatbed dryer.

In addition to the flatbed dryer shortage in terms of labour incentives and tempering reviewed above, the advantages of flatbed dryer such as simple, cheap, and so easy to make.

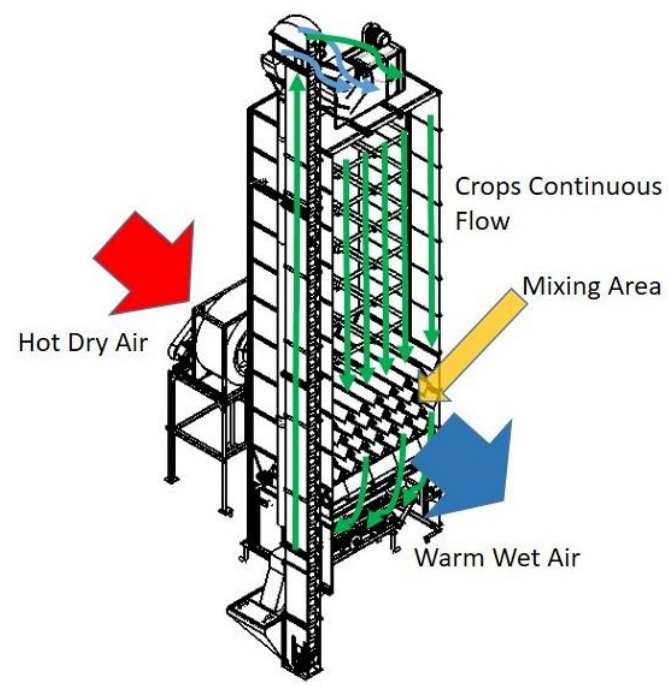

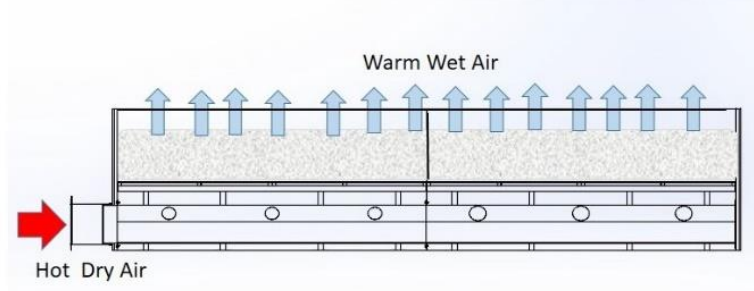

Fig. 6. Sketch of Flat Bed Dryer

In the traditional bed dryer, hot air is channelled through the bed's lower plenum space evenly through the expanse of grains above it. The dry hot air will penetrate from the bottom up through the seeds which are spread out due to the pressure of the blower and the nature of the hot air which is lighter than the ambient temperature air. The lowest layer of grains will automatically receive excess heat compared to the grains in the middle, and moreover the top layer, so it requires an effort to continuously stir.

In the traditional bed dryer, at least 4-5 operators are required to carry out continuous stirring of the grains so that the drying process can be evenly distributed throughout the pile of grains. It must also be noted that the build-up must be flat because the flow of hot air will always look for the smallest obstacles in penetrating the pile of grains. If there is a lower impact, the heat will be concentrated to flow in the area, not through a higher pile of grains. You can imagine the stirring power must be $8-10$ hours always stirring above the grains and hot air and the sharpness of silica which will always grind the skin of the operators. The sketch of flatbed dryer with stirring is stated in Fig. 7.

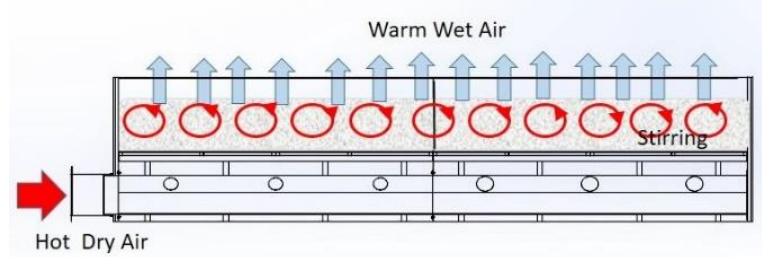

Fig. 7. Stirring needed to mix the Grains

The traditional bed dryer application usually uses diesel fuel as a calorie-producing fuel so that the consumption needed for the duration of drying 8-10 hours will be higher than the drying process using sunlight.

However, drying with the drying machine will be free to do drying whenever desired regardless of the quality of the sun, rainy weather conditions, day and night. If the approach of operating this machine is considered expensive by the farmer, even though the drying time is long, the farmer will return drying the grains using the old method open sun drying. For this reason, a mechanization breakthrough must be made that can overcome the problem above. The morphology Matrix can be seen in Table 1 .

Fig. 5. Sketch of the Vertical Dryer System 
Table 1. Morphology Matrix Table

\begin{tabular}{|c|c|c|c|}
\hline Process & Process Options & Id. & Options \\
\hline \multirow[t]{3}{*}{ Husk Transfer (A) } & Screw Conveyor & A1 & 10 (Inject). Need Pressure \\
\hline & Belt Conveyor & $\mathrm{A} 2$ & 3 (No Pressure) \\
\hline & Vibration Conveyor & A3 & 3 (No Pressure) \\
\hline \multirow[t]{3}{*}{ Burner (B) } & Direct Burner & $\mathrm{B} 1$ & 5 (Only good for Grains/Dirty Hot Air) \\
\hline & Cyclone Direct Burner & B2 & $\begin{array}{l}7 \text { (Control Blower is very risky to ensure dust is centered on the core of } \\
\text { the vortex) }\end{array}$ \\
\hline & Indirect Burner & B3 & 10 (Clean) \\
\hline \multirow[t]{2}{*}{ Stirrer $(\mathrm{C})$} & Electric Motor & C1 & 10 (Efficient in Manpower and can Control functions) \\
\hline & Manual Manpower & $\mathrm{C} 2$ & $\begin{array}{l}2 \text { (There are two movements for stirring, namely Translation along Bed } \\
\text { and Rotation. The power to rotate is hefty and the power to move the } \\
\text { translation is very difficult to realize. So that it requires a lot of human } \\
\text { resources and only avoids direct contact with silica, and possibly more } \\
\text { than four people for } 10-12 \text { hours nonstop.) }\end{array}$ \\
\hline \multirow[t]{2}{*}{ Moisture Tester (D) } & Manual & D1 & 10 (Because the Bed Dryer is not Premium drying) \\
\hline & Auto & D2 & $\begin{array}{l}7 \text { (It will still be inferior to Vertical Dryer which adopts a process dryer } \\
\text { system) }\end{array}$ \\
\hline
\end{tabular}

From the results of the Morphology Matrix table above, the following conceptualization was obtained: Given that the Additional Value to be touched on in this development only converges focus to two systems, namely alternative energy for producing heat; and the stirrer mechanism with the lightest but most effective power, the selection is very limited and refers to the use of rice husk or biomass, and stirrers from the top side of the grains because the nature of the bed dryer which the commodity is speeding out at the top of the screen above plenum chamber.

For this reason, the combination of development will converge to a combination of $\mathrm{A} 1+\mathrm{B} 3+\mathrm{C} 1+\mathrm{D} 1$

A1: Considering the heat energy chosen is husk/biomass (chipping), it requires energy suppressing the injected fuel in the form of husk to the burning chamber of the burner. Screw Conveyor is very precise and heat resistant.

B3: Indirect burner is needed to ensure the hot air that is channelled to the grains expanse is the air that is clean from dust from combustion. If the air still contains ash/dust and the commodity is still wet/moist, it will pollute the commodity which causes the quality of the dry grains to drop. This is fatal for open grains, no coating skin like soybeans and corn. For the selection of Direct Cyclone Burner, it will indeed be more energy efficient because it does not need to go through heat transfer media, but there is a risk of dust sticking if the cyclone vortex that occurs is imperfect. In the event of such imperfection, the commodity will immediately be exposed to dust so that it is permanently dirty (sticky with wet/sweaty skin).

$\mathrm{C} 1$ : There are two movements to stir the grains in the rectangle bed dryer that has dimensions; long, wide, high, namely Translation, and Rotation. To save energy, the translation movement must be along the effective length of the bedchamber. A rotational movement used to stir the grains as deep as the depth of the grains. To save energy, you should look for a movement configuration with as little energy as possible, but it is sufficient to evenly spread the movement of the grains. It is quite underlined and on the bold line because of the maximum energy limit of movement and the need to only make all moving grains receive flat dry air.

D1: In the drying duration of 8-10 hours, the reduction in water content will not change drastically so that RH monitoring can be carried out gradually by the same operator. So the concept of sampling tests can still be done. RH meter auto is used if the work function will be made fully auto control where if the grains reach a certain dryness, the PLC can set all systems both husk feeding to the Combustion chamber, air input blower, even stop the process if it has reached the desired criteria. Because the grains are not moving, so the sampling testing should consider checking 27 check spot points. 9 spots at the bottom layer, 9 spots at the middle and the other 9 spots at the top layer. The 9 points are spread out along $1 / 3$ of the length and width of each 
layer. This process is hard to do with an auto system. However, the bed dryer system will not be as good as or better than Vertical Dryer where grains are rotated approximately once every hour with $1 / 4$ for cross flowing with dry air and $3 / 4$ when it is aired. This concept is known as tempering [18]. The goal is to make a drying change between the skin of the grain's contents, and the core content of the grains can be homogeneous. The more similar the decline, the better quality of rice produced will be, especially on the side of the percentage of yield broken. Given the above considerations, the auto system at bed dryer is not needed. Simply a manual sampling system.

It is planned that a mechanical system that continuously performs stirring during drying time so that the grains at the bottom, middle, and top layers can be mixed homogeneously. In order not to reduce Value Creation, the total cost of investment and operations cannot be equal or enlarged. The drying production rate must be smaller, and also the investment cost up. There are two increasing variables must be calculated and controlled their value deeply, namely; Increase the driving force to stir for 8 hours. It takes 4-5 mixer operators for 8 hours. If the labour costs Rp 100,000 per process, it costs Rp. 350,000 per 8 hours or Rp. 43,750 per hour. If converted to electric power assuming a NonSubsidized TDL of Rp1,380, - per kWh (Validation Data), the maximum power limit is $32 \mathrm{~kW}$ or $43.5 \mathrm{HP}$.

The second variable is the price increase due to the addition of the stirring system. If the targeted price increase is not more than $35 \%$ or around $\mathrm{Rp} 48,510,000$ (selling price of Bed Dryer Husk burner without stirrer is Rp. 138,600,000) or if in 1 year it is targeted to operate for 450 processes (300 days @ 3 methods/ 2 days), the maximum increase in the price of the stirrer system is converted to power costs equivalent to $15.62 \mathrm{~kW}$ or 21.24 HP.

For this reason, an effective stirring mechanism must be designed with additional power which should not be more than or equal to $22.26 \mathrm{HP}(43.5 \mathrm{HP}-21.24 \mathrm{HP})$, if the breakthrough is intended to deliver the additional value of husk bed dryer machine without a stirrer.

There are two movements in the stirring system. First, translation movement along the long side of the bed with the stirrer axis along the bed width powered by electric motor. The translation movement from the steering shaft is moved by chains and controlled by some limit switch at the end of the rails. The concept of the mixing movement can be seen in Fig. 8. The system will change the direction of movement every time the shaft touches the limits. The second movement is the rotating shaft. We put $2^{\text {nd }}$ electric motor plus gearbox to rotate the shaft clockwise and vice versa following the direction of the movement.

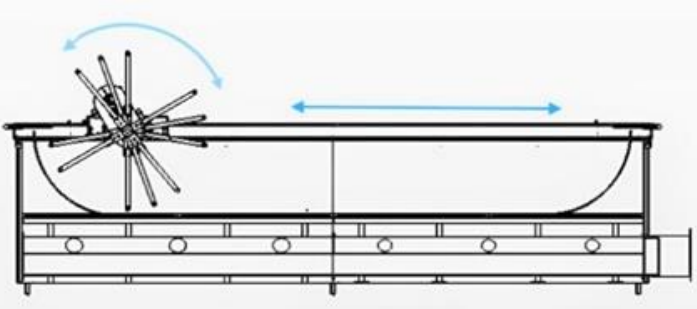

Fig. 8 Concept of Mixing Movement

The stirrer system moves in translation and rotation forms with the speed and direction of rotation which is matched with the calculation of the electric motor power, but still able to homogenize the dryness of grains throughout the bed overlay point. Both of these two electric motors' power cannot be more than 21.24 HP. The system sits independently on the structure of the stirrer/frame system itself, without overloading the bed. The dead corner space in the unreached area should be closed.

Table 2. Drying Rate Comparation

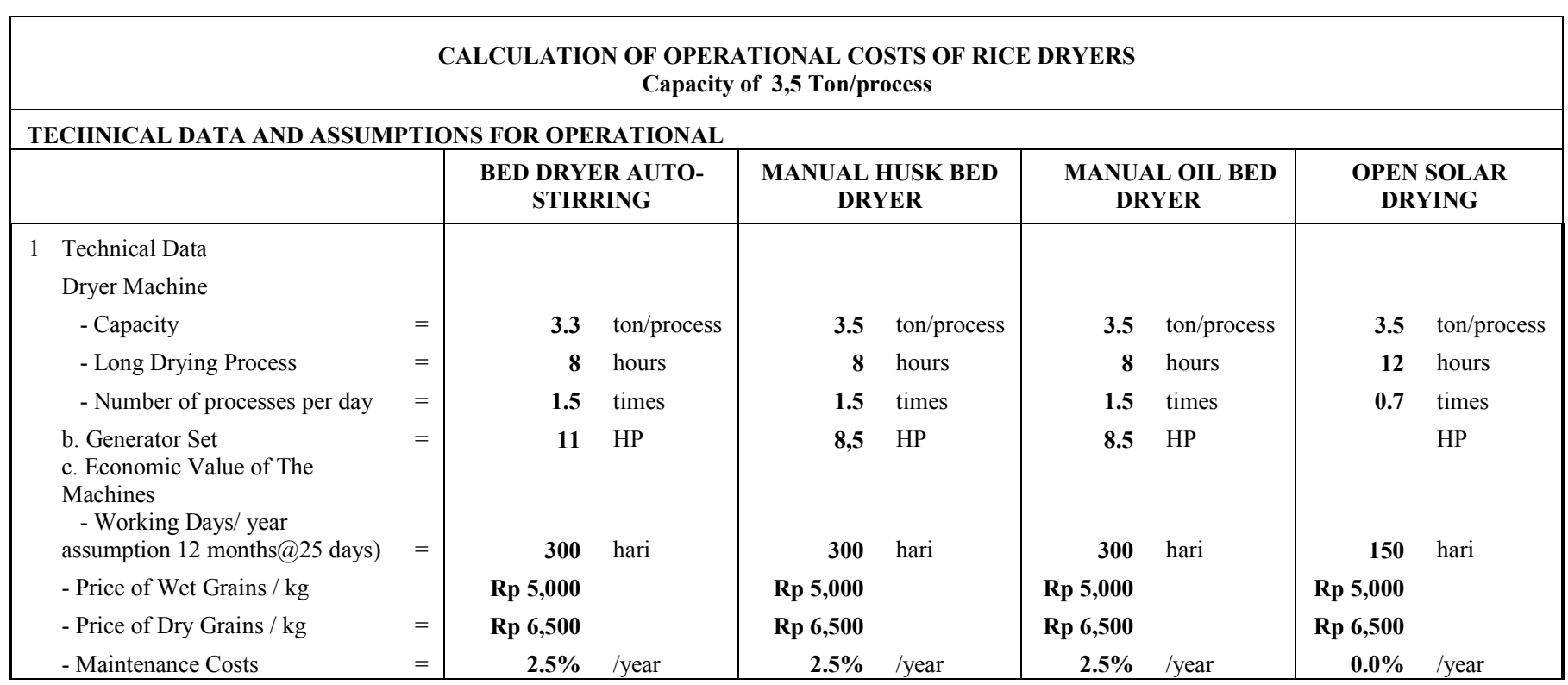




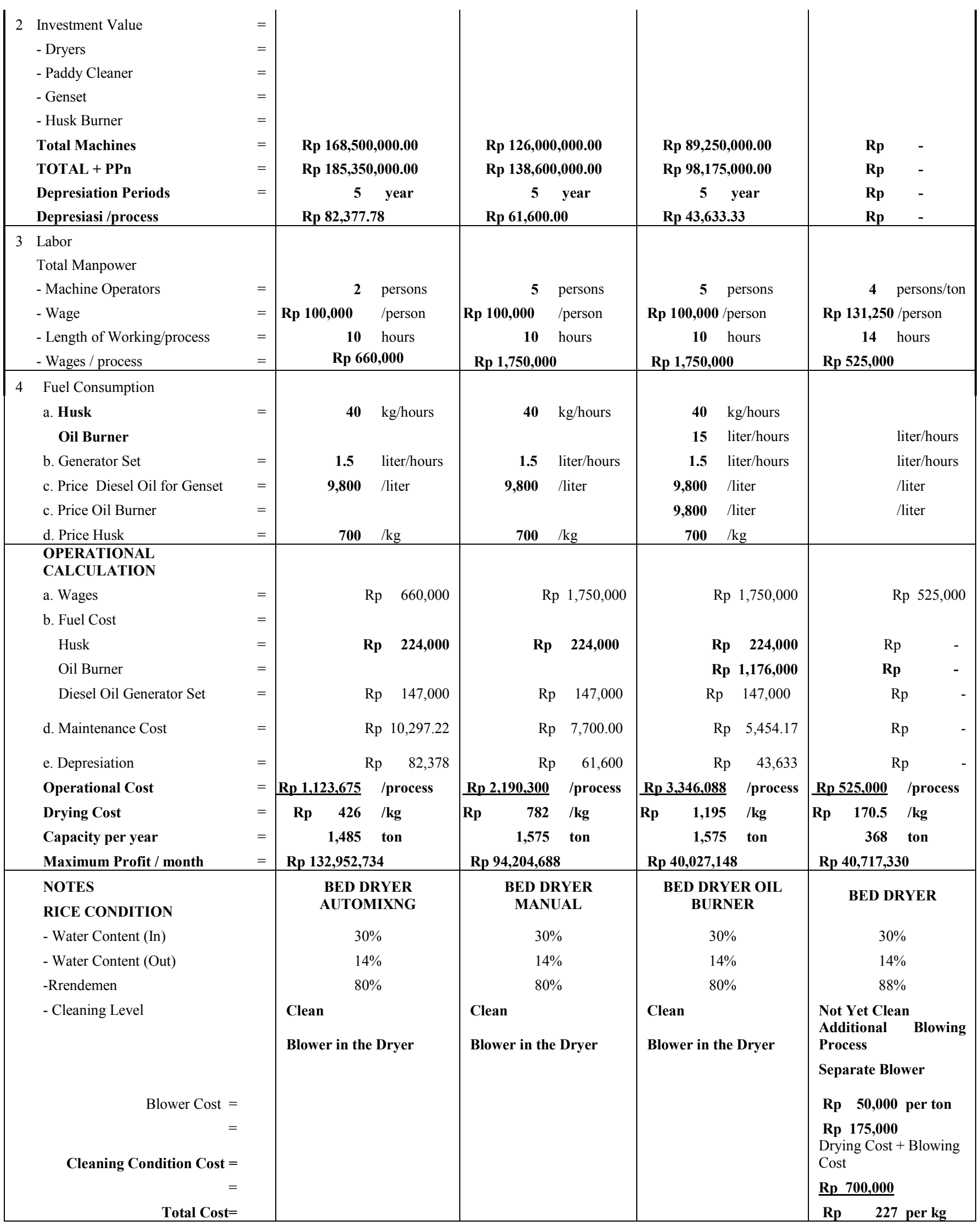

\section{NOTES:}

1. The drying process of the Open Solar Drying for 12 hours starts from 08.00 - 15.00 WIB then resumes the next day from 08.00 11.00 WIB

2. The price of Diesel fuel used uses non-subsidized diesel fuel Rp. 9.800

3. Wages for Open Solar Drying workers are calculated in bulk Rp. 150 per kiligram ( $R p 150 \times 3.500 \mathrm{~kg}=\mathrm{Rp} .525 .000: 4$ or ng $=$ Rp.131.250) 


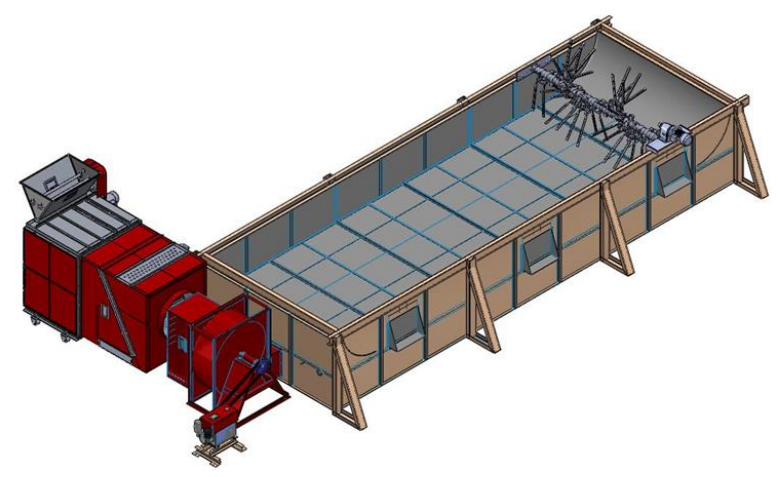

Fig. 9. Isometric Drawing

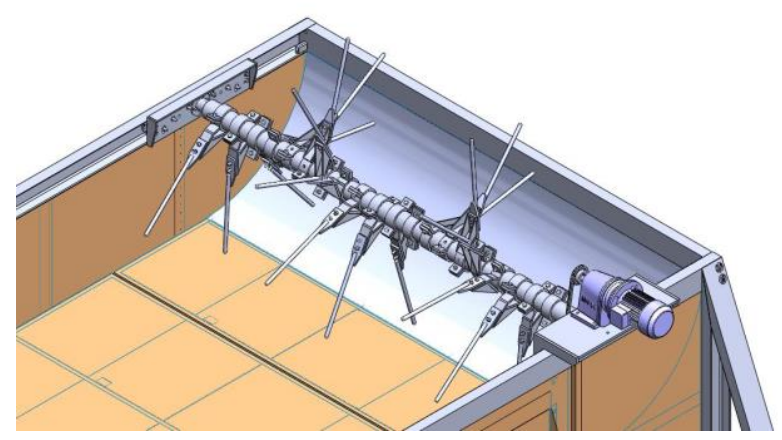

Fig. 10. Stirring Assy System

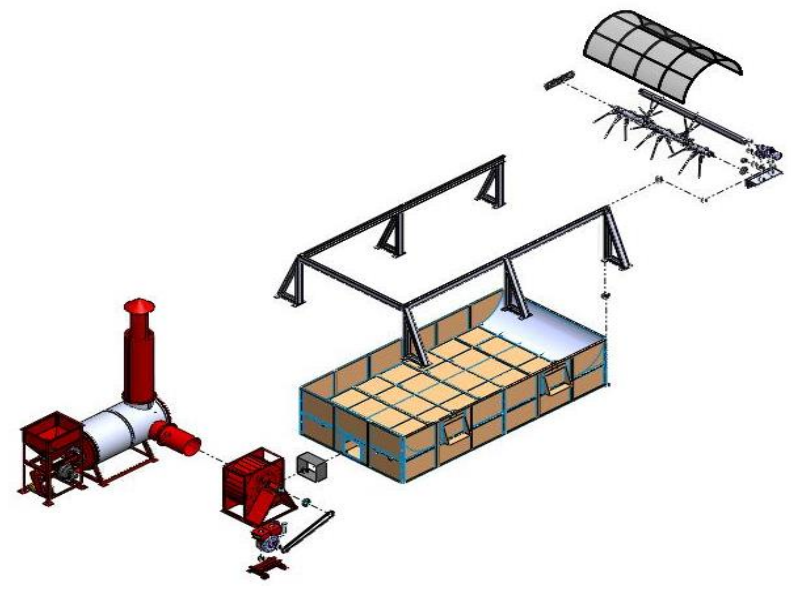

Fig. 11. Exploded View

\section{Conclusion}

The use of rice husk as a substitute fuel for heat generator is appropriate both economically and environmentally. Mainly because the rice husk used is waste from the milling process, the next process after drying where the grains are peeled with husker machine and then continued with a variety of processes which usually followed by the polishing process. Rice husk that is used as fuel will not add to the effects of global warming because carbon released from the combustion process is the same amount of carbon absorbed during the process of growing rice.
In the future, rice husk ash also will become the strategic economic material for special purpose especially of silica content produced (Zeolite NaY, Synthetic and Polymer industries) and the form of ash shape for construction and ceramic industries.

From Table 2 we can see that although the cost of drying the method of open sun drying is very cheap because all the practical costs are only variable costs, but due to the length of the drying process, and many uncontrollable factors the profit received by farmers is much smaller than the farmers who invest and use dryers.

With this Engineering Design/Product Design method finally, a stirrer mechanism is made in which the additional driving power is much smaller than the maximum power setting, so the result is a breakthrough creating value for the previous process. Details of the resulting value can be seen in Table 2. Farmers' income for this innovative modification resulted in a $332 \%$ increase in profit/welfare from the previous process that using the standard diesel fuel flatbed dryer machine, and a $41 \%$ increase in welfare compared to the standard rice husk flatbed dryer machine (without stirring system).

\section{References}

1. W. Shen, S.C.S. Yang, L.F. Zanna, J.D. Econ, Government Spending Effects in Low-Income Countries, Accepted Manuscript (2018)

2. R. Tyers, A. Rachman, Consumption Diversification and Foreign Exchange Balances in Indonesia: Results from a Multi-Comodity Simulation, J. Policy Model. 3, 363 (1982)

3. J. Gaffney, M. Challender, K. Califf, K. Harden, Building Bridges Between Agribusiness Innovation and Smallholder Farmers: A Review. Glob Food Sec. 154, 1 (2019)

4. N.V. Hung, R. Quilloy, M. Gummert, Improving Energy Efficiency and Developing An Air-Cooled Grate for The Downdraft Rice Husk Furnace, Renew. Energy 115, 969 (2018)

5. I. Rice, K. Bank, Traditional Drying Systems, 1-4 (2019)

6. J. Rickman, Paddy Drying Systems. IRRI Rice Knowledge Bank (2004)

7. P. Lerman, O. Wennberg, Experimental Method for Designing A Biomass Bed Dryer. Biomass and Bioenergy 35 (S31), S31-S39 (2011)

8. S. Tiwari, G.N. Tiwari, I.M. Al-Helal, Development and Recent Trends in Greenhouse Dryer: A Review, Renew Sustain Energy Rev. 65, 104 (2016)

9. M. Kumar, S.K. Sansaniwal, P. Khatak, Progress in Solar Dryers for Drying Various Commodities. Renew Sustain Energy Rev. 55, 346 (2016)

10. V. Tomar, G.N. Tiwari, B. Norton, Solar Dryers for Tropical Food Preservation: Thermophysics of Crops, Systems, and Components. Sol Energy 154, 2 (2017)

11. D. Harsoekoesmono, Introduction to Engineering Design, Publisher ITB (2004)

12. I.J. Fernandes, D. Calheiro, A.G. Kieling, C.A.M. 
Moraes, T.L.A.C. Rocha, F.A. Brehm, et al, Characterization of Rice Husk Ash Produced using Different Biomass Combustion Techniques for Energy. Fuel 165, 351 (2016)

13. A.K. Shukla, K. Sudhakar, P. Baredar, Renewable Energy Resources in South Asian Countries: Challenges, Policy, and Recommendations. Resour Technol. 3, 342 (2017)

14. I. Quispe, R. Navia, R. Kahhat, Energy Potential from Rice Husk Through Direct Combustion and Fast Pyrolysis: A Review. Waste Manag. 59, 200 (2017)

15. P.L. Fernández, F. Pablos, M.J. Martí, A.G. González, Study of Catechin and Xanthine Tea Profiles As Geographical Tracers, J Agric Food Chem. 50, 1833 (2002)

16. S.A. Holowaty, L.A. Ramallo, M.E. Schmalko, Intermittent Drying Simulation in A Deep Bed Dryer of Yerba Maté. J Food Eng. 11, 110 (2012)

17. W. Jittanit, N. Saeteaw, A. Charoenchaisri, Industrial Paddy Drying and Energy Saving Options. J Stored Prod Res. 4, 209 (2010)

18. M.S.H. Sarker, M.N. Ibrahim, N.A. Aziz, P.M. Salleh, Energy and Rice Quality Aspects During Drying of Freshly Harvested Paddy with Industrial Inclined Bed Dryer. Energy Convers Manag. 77, 389 (2014) 